\title{
Antigenic contents of Treponema pallidum preparations
}

\author{
SUSAN M WOS*, AND KONRAD WICHER* $\dagger$ \\ From the *Wadsworth Center for Laboratories and Research, New York State Department of Health, Albany, New \\ York, and the †Department of Microbiology, School of Medicine, State University of New York at Buffalo, Buffalo, \\ New' York, United States of America
}

SUMMARY In investigations of syphilis various Treponema pallidum antigens are used to study the immune responses of naturally or experimentally infected hosts. In the past these antigen preparations have rarely been examined for their antigenic contents and activity. In the present study, supernatant, sediment, and solubilised preparations of $T$ pallidum Nichols strain $\left(20 \times 10^{9}\right.$ organisms $/ \mathrm{ml}$ ) and $T$ phagedenis biotype Reiter were examined by modified counterimmunoelectrophoresis and immunoblotting for their antigenic contents. No $T$ pallidum antigen was seen in the supernatant fraction, which contained cross reacting (Reiter) antigens and rabbit serum proteins. The remaining $T$ pallidum preparations contained $T$ pallidum antigens, cross reacting treponemal (Reiter) antigens, and rabbit serum proteins.

These findings suggest that $T$ pallidum preparations should be examined qualitatively and quantitatively before they are used for monitoring immune responses and interpreting data. Technology for these examinations is available.

\section{Introduction}

Eighty years of research into syphilis has contributed greatly to the diagnosis and treatment of the disease but little to our understanding of the caustive agent, Treponema pallidum, and the immunopathology of the infected host. The major reason for this lack of progress is the complexity of the organism and the inability so far to culture it in vitro in a cell free medium. Instead, the treponemes used for various diagnostic or research purposes are propagated in rabbit testes. Separating treponemal antigen from host proteins and isolating and purifying species specific antigens is extremely difficult.

In studies during years of research the immune responses of hosts infected with $T$ pallidum have been assessed by using various $T$ pallidum preparations, including intact organisms ${ }^{1-3}$ and sonicated, ${ }^{45}$ sonicated and centrifuged, ${ }^{6}$ or cryolysed, sonicated, and centrifuged material. ${ }^{7}$ Very rarely were these antigen preparations examined for their antigenic activity. ${ }^{8}$ To our knowledge, there have been no published reports relating to immune response studies in which the concentration of specific Tpallidum in the

Address for reprints: Dr Konrad Wicher, Wadsworth Center for Laboratories and Research, New York State Department of Health, Albany, New York 12201, USA

Accepted for publication 12 September 1985 assay antigen has been measured. The varying concentrations, purity, and specificity of these preparations could account in part for the discrepancies between the reported data.

Future investigations on measuring immune responses to infection with $T$ pallidum depend on the answers to following key questions: how much of the specific antigen is present in a given $T$ pallidum preparation, how important is it to measure specific responses, and will they differ from those obtained with the complex crude treponemal antigen?

\section{Material and methods}

\section{REAGENTS}

$T$ pallidum Nichols is maintained in our laboratory by intratesticular passage in adult Nys (Flemish Giant) rabbits, ${ }^{9}$ which were used to obtain $T$ pallidum preparations and antisera for the present study. Intratesticular infection was accomplished by inoculation of $20 \times 10^{6}$ organisms per testis. At the time of orchitis, nine to 12 days after infection, the organisms were extracted repcatedly from the orchitic tissue into phosphate buffered saline (PBS), $\mathrm{pH} 7 \cdot 2(20$ $\mathrm{ml} /$ testis). The suspensions were_filtered through polycarbonate filters with $0.8 \mu \mathrm{m}$ sized pores (Nucleopore Corporation, Pleasanton, California, USA), and the organisms were pelleted by centrifugation at $39100 \times g$ for one hour, followed by three washes in excess PBS. A suspension of $20 \times 10^{9}$ 
organisms/ml was sonicated (MSE Incorporated, Westlake, Ohio, USA) for six to eight cycles of one minute each until all the organisms were disrupted, as confirmed by dark field microscopy. The sonicate was centrifuged at $39100 \times g$ for one hour. The supernatant was removed, and the sediment was resuspended to the original volume with PBS.

Solubilised $T$ pallidum antigen was prepared from a filtered suspension containing $20 \times 10^{9}$ organisms $/ \mathrm{ml}$ in $10 \mathrm{mmol} / 1$ tromethamine (TRIS) and $1.5 \mathrm{mmol} / 1$ disodium ethylenediamine tetraacetate, $\mathrm{pH} 7 \cdot 2$. The organisms were sonicated as described above. Sodium-N-lauryl sarcosine was added to a final concentration of $2 \%$, and the solution was incubated at $37^{\circ} \mathrm{C}$ for 30 minutes with constant stirring.

Treponema phagedenis biotype Reiter was grown in spirochaetal medium with $10 \%$ rabbit serum. ${ }^{10}$ Washed organisms were adjusted to $20 \times 10^{9}$ organisms $/ \mathrm{ml}$ and used to prepare supernatant, sediment, and solubilised fractions as for $T$ pallidum.

Normal rabbit serum and normal rabbit testicular fluid were used as controls. Normal rabbit testicular fluid was prepared from five rabbits by aseptically removing the testes, cutting each in half, and centrifuging each half at $12000 \times g$ for 30 minutes. The transudate was centrifuged at $39000 \times g$ for one hour. All antigen preparations were aliquoted and stored at $-70^{\circ} \mathrm{C}$ until used.

Antiserum to $T$ pallidum was obtained from eight rabbits by nine intravenous injections with virulent $T$ pallidum Nichols strain ( 20 to $50 \times 10^{6}$ organisms) during a three month period. An IgG fraction, prepared by diethylaminoethanol (DEAE) chromatography, ${ }^{11}$ was adsorbed with glutaraldehyde polymerised normal rabbit serum and normal rabbit testicular fluid, ${ }^{12}$ followed by adsorption with cyanogen bromide activated Sepharose gel coupled with sonicated $T$ phagedenis Reiter $(8 \mathrm{mg}$ protein $/ \mathrm{ml}$ gel).

Rabbit antiserum to $T$ phagedenis Reiter was prepared by immunising the animals with washed organisms $\left(10^{10} / \mathrm{ml}\right)$ emulsified in complete Freund's adjuvant. The animals received four bimonthly intradermal injections at multiple sites (eight to ten). The antiserum was adsorbed with glutaraldehyde polymerised normal rabbit serum.

Titres of antibodies to $T$ pallidum and $T$ phagedenis biotype Reiter and the effects of adsorptions were measured by the fluorescent antibody test or by modified counterimmunoelectrophoresis.

Antisera to host proteins were prepared by immunising guinea pigs with normal rabbit testicular fluid or normal rabbit serum preparations emulsified in complete Freund's adjuvant. Five intradermal injections $(0.5 \mathrm{~g} / \mathrm{l})$ were given over six months. The titres were measured by counterimmunoelectrophoresis.

\section{Counterimmunoelectrophoresis}

We used a two step modification of counterimmunoelectrophoresis (Dr Victoria Wicher, unpublished observation). A $1.5 \mathrm{~mm}$ thick gel slab was prepared by pouring $15 \mathrm{ml}$ of $1 \%$ agarose prepared in barbital buffer ( $\mathrm{pH} 8.6)$ on to a glass plate. Pairs of wells $3 \mathrm{~mm}$ in diameter were punched $6 \mathrm{~mm}$ apart in a row down the plate. The anodal wells were filled with $10 \mu l$ of antiserum and electrophoresed at $250 \mathrm{~V}$ for 20 minutes. The cathodal wells were then filled with $10 \mu \mathrm{l}$ of the appropriate antigen and electrophoresed for an additional 30 minutes. The slides were washed for three days with frequent changes of PBS and soaked overnight in half strength barbital buffer to equilibrate the agarose. After removing fluid from the wells, an immunoglobulin fraction $(10 \mathrm{~g} / \mathrm{l})$ of antirabbit or antigoat antiserum was added to the anodal wells. The gels were electrophoresed under the same conditions as described previously. The plates were then washed and stained and the results read.

\section{Fluorescent antibody test}

We performed the test as described previously. ${ }^{13}$ In general, heat inactivated serum samples were applied on Treposlides (Beckman Instruments, Fullerton, California, USA), incubated at $37^{\circ} \mathrm{C}$ for 30 minutes, and washed. Antiserum conjugated with fluorescein isothiocyanate (fluorescein to protein ratio 2.8 ) was then applied and after being washed the slides were examined under a Nikon Optiphot microscope.

\section{Western blot technique}

We examined supernatant and sediment fractions of various concentrations of $T$ pallidum as described previously. ${ }^{14}$ The treponemal preparations were electrophoresed on a $10 \%$ polyacrylamide slab gel in a TRIS-glycine system, as described by Laemmli. ${ }^{15}$ Proteins were electrophoretically transferred on to nitrocellulose paper ${ }^{16}$ in a Trans-Blot Cell (Bio Rad Laboratories, Richmond, California, USA) with TRIS-glycine-methanol buffer at $8 \mathrm{~V} / \mathrm{cm}$ for three hours at $4^{\circ} \mathrm{C}$. The nitrocellulose blots were probed for two hours with antiserum to $T$ pallidum adsorbed with normal rabbit testicular fluid, normal rabbit serum, and Treponema phagedenis Reiter.

\section{Results}

The minimum concentrations of antigens detected by the modified counterimmunoelectrophoresis were: $T$ pallidum, $60 \mu \mathrm{g} / \mathrm{ml} ; T$ phagedenis Reiter, $2 \mu \mathrm{g} / \mathrm{ml}$; and normal rabbit serum, $0.2 \mu \mathrm{g} / \mathrm{ml}$.

Both $T$ pallidum and $T$ phagedenis Reiter preparations were assayed for treponemal and host antigens by counterimmunoelectrophoresis. The table summarises the results. Adsorption of $T$ pallidum antiserum with $T$ phagedenis Reiter eliminated 
TABLE Detection of antigens by counterimmunoelectrophoresis

\begin{tabular}{|c|c|c|c|c|c|c|}
\hline \multirow[b]{3}{*}{ Antisera } & \multicolumn{6}{|l|}{ Reaction with: } \\
\hline & \multicolumn{3}{|c|}{ Treponema pallidum Nichols strain } & \multicolumn{3}{|c|}{ Treponema phagedenis biotype Reiter } \\
\hline & Supernatant & Sediment & Solubilised & Supernatant & Sediment & Solubilised \\
\hline $\begin{array}{l}T \text { pallidum Nichols } \\
T \text { phagedenis Reiter } \\
\text { Normal rabbit serum } \\
\text { Normal rabbit testicular fluid }\end{array}$ & $\begin{array}{l}- \\
+ \\
+ \\
-\end{array}$ & $\begin{array}{l}+ \\
+ \\
+ \\
-\end{array}$ & $\begin{array}{l}+ \\
+ \\
+ \\
-\end{array}$ & $\begin{array}{l}- \\
+ \\
+\end{array}$ & $\begin{array}{l}- \\
+ \\
+\end{array}$ & $\begin{array}{l}- \\
+ \\
+\end{array}$ \\
\hline
\end{tabular}

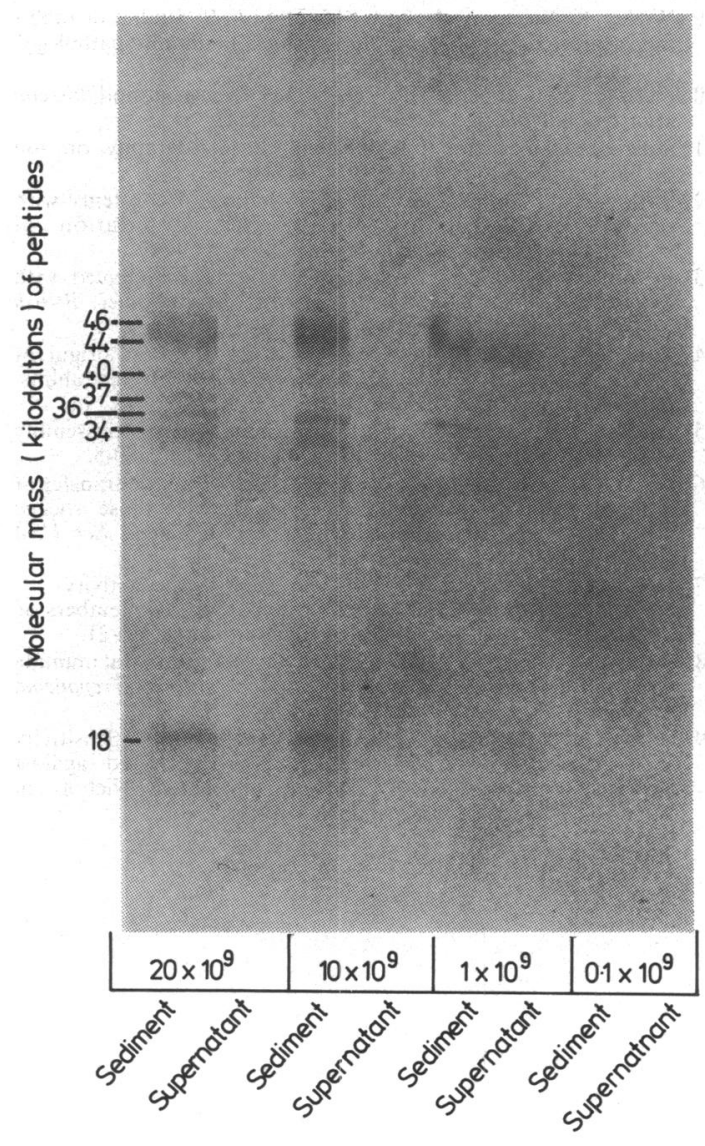

FIGURE Detection of Treponema pallidum Nichols antigens by western blot technique. Preparations containing $0.1 \times 10^{9}$ to 20 $\times 10^{9} \mathrm{~T}$ pallidum nere processed to obtain sediment and supernatant fractions, which were reacted with absorbed antiserum to $T$ pallidum. (T $T$ pallidum antigens were detected in three sediments $\left(1 \times 10^{9}\right.$ to $\left.20 \times 10^{9}\right)$ but not in the supernatants.) detectable cross reactivity to this organism. The adsorbed antiserum detected $T$ pallidum antigens only in $T$ pallidum sediment and solubilised preparations. No $T$ pallidum antigens were detected in $T$ pallidum supernatant, which contained cross reacting treponemal (Reiter) antigens and rabbit serum proteins. No testicular proteins were detected in any $T$ pallidum preparation. All three preparations of $T$ phagedenis Reiter contained treponemal antigens and rabbit serum proteins.

To confirm the absence of $T$ pallidum antigens in $T$ pallidum supernatant, this and $T$ pallidum sediment preparations of various concentrations of $T$ pallidum were examined by the western blot technique with the adsorbed antiserum to $T$ pallidum. No $T$ pallidum antigens were detected in T pallidum supernatant, even at the highest concentration of $T$ pallidum (figure). The $T$ pallidum sediment preparation contained $T$ pallidum antigen, which decreased with decreasing concentrations of $T$ pallidum. The molecular masses of the reactive peptides in $T$ pallidum ranged from 46 to 18 kilodaltons. Peptides with molecular masses greater than 46 kilodaltons, which had been reported previously in solubilised $T$ pallidum preparations, ${ }^{141718}$ were absent from $T$ pallidum sediment. Our antiserum, however, had been absorbed to the point of not reacting by counterimmunoelectrophoresis with cross reactive Reiter antigens.

\section{Discussion}

No information is available on the sensitivity of the western blot technique. About $10^{8}$ to $10^{10} T$ pallidum micro-organisms are most commonly used. ${ }^{141718}$ The solid phase immunoblot assay, however, which is a modification of the colony blot radioimmunoasay, showed positive reactions with as few as $1000 T$ pallidum organisms when used to analyse monoclonal antibodies. ${ }^{19}$

The sensitivity of any immulogical test using the $T$ pallidum system is influenced by the presumably weak avidity of the antibodies and the degree of specificity of the antiserum. Before adsorption our antiserum to $T$ pallidum had a fluorescent antibody titre of $1 / 10000$, which decreased to $1 / 8000$ after repeated 
adsorptions with a suspension of intact washed Treponema phagedenis Reiter ( $10^{10}$ organisms). After two further adsorptions with sonicated Reiter organisms coupled to cyanogen bromide activated Sepharose the titre decreased to $1 / 4000$, which indicates that adsorption with the intact organism removes only part of the cross reacting antibodies. This antiserum no longer reacted with Reiter antigens or with normal rabbit serum by counterimmunoelectrophoresis.

The results of the present study indicate that $T$ pallidum supernatant did not contain measurable $T$ pallidum antigen, even when the original concentration of the suspension was $20 \times 10^{9}$ organisms $/ \mathrm{ml}$. Even if $T$ pallidum antigen is present in minute amounts in the supernatant, it must be overwhelmed in the competition with cross reacting treponemal antigens and host serum proteins.

We therefore conclude that the $T$ pallidum supernatant is not a suitable reagent for measuring the immune response in hosts infected with $T$ pallidum. Moreover the $T$ pallidum sediment fraction obtained from a suspension of $10^{8} \mathrm{~T}$ pallidum $/ \mathrm{ml}$ does not have a measurable amount of treponemal antigen. The techniques of the immunoblotting system are available and should be used in qualitative analysis of treponemal reagents.

Strictly defined specific antigens should be used to re-examine the kinetics of the humoral and cellular response of hosts infected with $T$ pallidum.

References

1 Musher DM. Schell RF. Jones RH, Jones AM. Lymphocyte transformation in syphilis: in vitro correlate of immune suppression in vivo? Infect Immun 1975:11:1261-4.

2 Pavia CS. Folds JD, Baseman JB. Selective in vitro response of thymus-derived lymphocytes from Treponema pallidum-infected rabbits. Infect Immun 1977:18:603-11.
3 Maret SM, Baseman JB, Folds JD. Cell-mediated immunity in Treponema pallidum infected rabbits: in vitro response of splenic and lymph node lymphocytes to mitogens and specific antigens. Clin Exp Immunol 1980;39:38-43.

4 Metzger M, Podwinska J, Smogor W. Cell mediated immunity in experimental syphilis in rabbit. Arch Immunol Ther Exp (Warsz) 1977;25:25-34

5 Pedersen, NS, Axelsen NH, Petersen CS. Antigenic analysis of Treponema pallidum: cross-reactions between individual antigens of $T$ pallidum and T Reiter. Scand J Immunol 1980;13:143-50.

6 Lukehart SA, Baker-Zandar SA, Sell S. Characterization of lymphocyte responsiveness in early experimental syphilis. I. In vitroo response to mitogens and Treponema pallidum antigens. J Immunol 1980;124:454-60.

7 Wicher $\mathrm{V}$, Wicher $\mathrm{K}$. In vitro cell response of Treponema palliduminfected rabbits. I. Lymphocyte transformation. Clin Exp Immunol 1977;24:480-6.

8 Wicher $\mathrm{V}$, Wicher $\mathrm{K}$. Cell response in rabbits infected with $T$ pallidum as measured by the leucocyte migration inhibition test. British Journal of Venereal Diseases 1975;51:240-5.

9 Wicher K, Wicher V, Nakeeb SM, Dubiski S. Studies of rabbit testes infected with Treponema pallidum. I. Immunopathology. British Journal of Venereal Diseases 1983;59:349-58.

10 Hanson AW, Cannefax GR. Recovery of Treponema and Borrelia after lyophilization. J Bacteriol 1964;88:811.

11 Sober HA, Peterson EA. Protein chromatography on ion exchange cellulose. Fed Proc 1958;17:1116-26.

12 Avrameas S, Ternyck T. The cross-linking of proteins with glutaraldehyde and its use for the preparation of immunoabsorbents. Immunochemistry 1969;6:53-66.

13 Wicher V, Wicher K. Studies of rabbit testes infected with Treponema pallidum. II. Local synthesis of antibodies. British Journal of Venereal Diseases 1983;59:359-63.

14 Wos SM, Wicher K. Antigenic evidence for host origin of exudative fluids in lesions of Treponema pallidum-infected rabbits. Infect Immun 1985;47:228-33.

15 Laemmli UK. Cleavage of structural proteins during the assembly of the head of bacteriophage T4. Nature 1970;227:680-5

16 Towbin HT, Staehelin T, Gordon J. Electrophoretic transfer of proteins from polyacrylamide gels to nitrocellulose sheets: procedure and some application. Proc Natl Acad Sci USA 1979;76:4350-4.

17 Baker-Zander SK, Lukehart SA. Antigenic cross-reactivity between Treponema pallidum and other pathogenic members of the family Spiroehaetaceae. Infect Immun 1984;46:116-21.

18 Hanff PA, Bishop NH, Miller JN, Lovett MA. Humoral immune response in experimental syphilis to polypeptides of Treponema pallidum. J Immunol 1983;131:1973-7.

19 Norgard MV, Selland CK, Kettman R Jr, Miller JN. Sensitivity and specificity of monoclonal antibodies directed against antigenic determinants of Treponema pallidum Nichols in diagnosis of syphilis. Infect Immun 1984;20:711-7. 